\title{
RESEARCH ON SHORT-CIRCUIT IMPEDANCES OF NEW CONVERTER TRANSFORMER
}

\author{
TRAN THANH NGOC \\ Industrial University of Ho Chi Minh City \\ tranthanhngoc@iuh.edu.vn
}

\begin{abstract}
The short-circuit impedance of converter transformers is one of the most important specifications in HVDC system. Compared with the traditional converter transformers, the new converter transformer has unique windings connection diagrams. Based on the topological structure of the new converter transformer, this paper proposes a new method to establish the mathematical relationship of short-circuit impedances and filters impedances under considering the valve side and grid side shortcircuit conditions. The analysis on short circuit at valve side and grid side shows that short-circuit impedances values are almost the same in both two conditions, so that the impedance of the new converter transformer is symmetrical. Finally, simulation and experimental results verify the correctness of the theoretical analysis.
\end{abstract}

Keywords. HVDC, New converter transformer, Short-circuit impedance, Inductive filter.

\section{INTRODUCTION}

\subsection{The new converter transformer}

The conventional converter transformer $(\mathrm{Y} / \Delta / \mathrm{Y})$ is an important device in 12-pulse diode/SCR converters. It provides a phase displacement between primary side and valve side voltages for harmonic cancellation, supplies a proper valve side voltage, and also makes an electric isolation between the rectifiers and the utility supply. The configuration of a 12-pulse converter is shown in Figure 1, where the $A C$ filters are placed at the $A C$ bus, $U_{\text {load }}$ is the phase voltage of the valve side, and $Z_{R}$ is the impedance of power supply. [1-4]

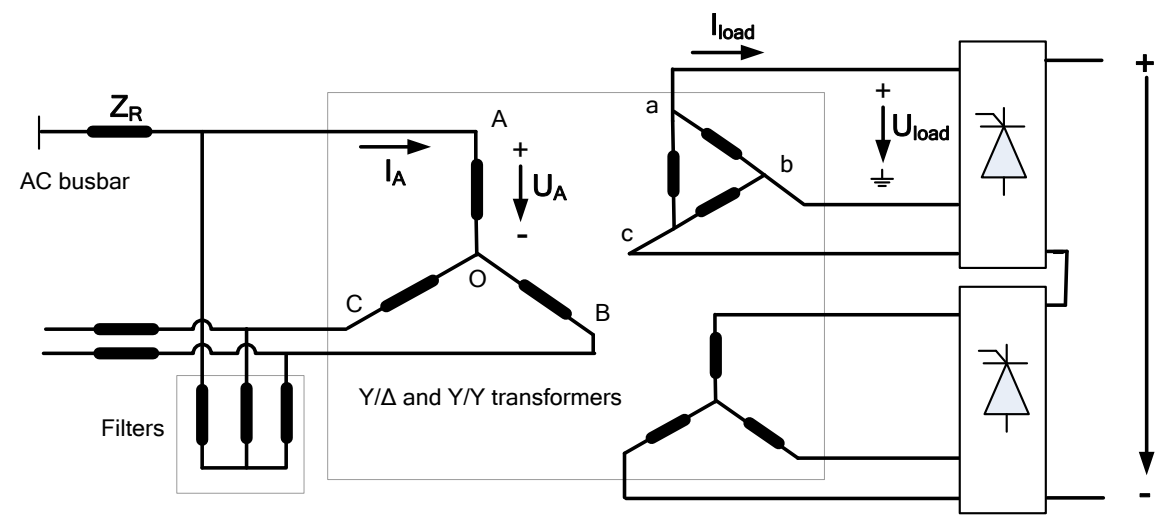

Figure 1: The winding connection scheme of the $\mathrm{Y} / \Delta / \mathrm{Y}$ transformers in the 12-pluse converter

Unlike the conventional converter transformer (CCT), the new converter transformer with its filters is a special kind of converter transformer whose grid side windings are connected to power grid, the valve side windings are connected to the rectifier, and the common side windings are connected to the filters. Similar to the conventional converter transformers of 12 pulses line commutated converter HVDC with $Y / \Delta / Y$ winding connection, the new converter transformer also has an upper and lower bridge which corresponds to $\Delta$ and $Y$ respectively [5-10]. The configuration of a 12-pulse converter is shown in Figure 2. 


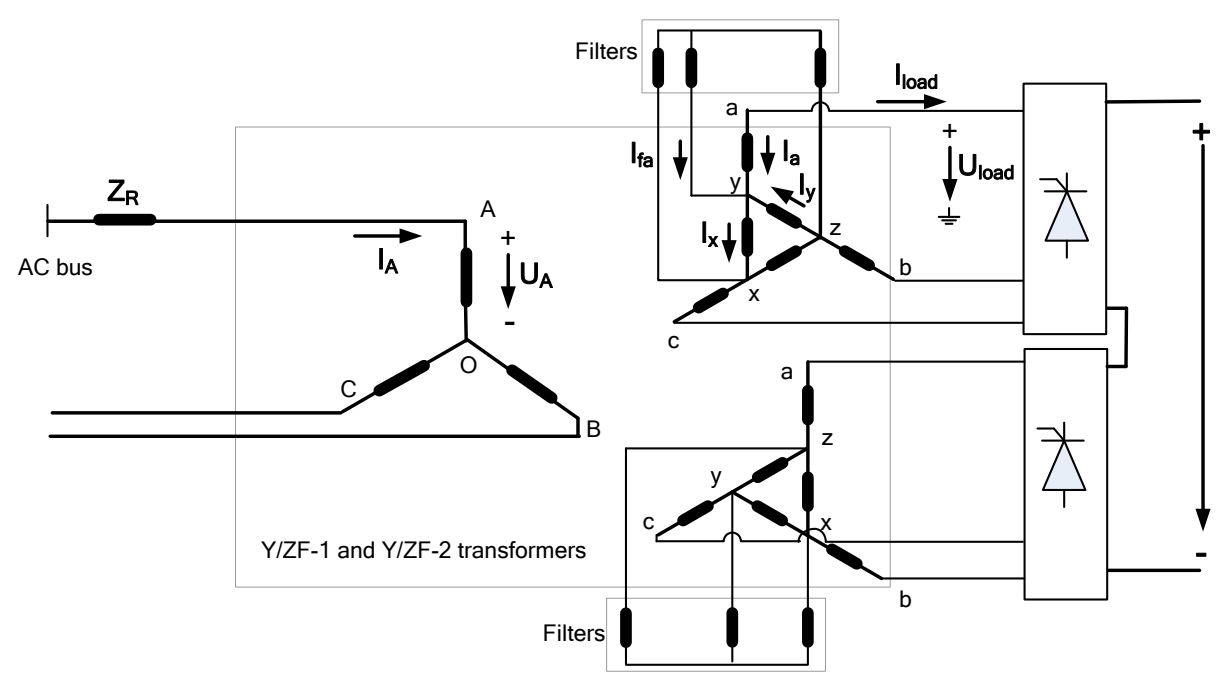

Figure 2: The winding connection scheme of the Y/ZF-1/ ZF-2 transformers in the 12-pluse converter

According to the theory of multi-winding transformer, the mathematical models of the Y/ZF-1 new converter transformers can be written as

$$
\begin{gathered}
\dot{I}_{A}=-k_{a} \dot{I}_{a}-k_{x} \dot{I}_{x} \\
\left\{\begin{array}{l}
\dot{U}_{a y}=k_{a} \dot{U}_{A}+k_{a}^{2} Z_{13} \dot{I}_{a}+k_{a} k_{x} Z_{1} \dot{I}_{x} \\
\dot{U}_{y x}=k_{x} \dot{U}_{A}+k_{x}^{2} Z_{12} \dot{I}_{x}+k_{a} k_{x} Z_{1} \dot{I}_{a}
\end{array}\right.
\end{gathered}
$$

where:

$Z_{12}=Z_{1}+Z_{2}^{\prime}, Z_{13}=Z_{1}+Z_{3}^{\prime}, Z_{23}=Z_{2}^{\prime}+Z_{3}^{\prime}, Z_{1}, Z_{2}^{\prime}, Z_{3}^{\prime}:$ are the impedance of the grid side, common side and valve side winding, respectively.

$\dot{I}_{A}, \dot{U}_{A}, Z_{1}, W_{1} ; \dot{I}_{x}, \dot{U}_{y x}, Z_{2}^{\prime}, W_{2} ; \dot{I}_{a}, \dot{U}_{a y}, Z_{3}^{\prime}, W_{3}$ : are the phasor current, phasor voltage, phasor impedance and number of turns of the grid side winding (AO winding); common side winding ( $\mathbf{y x}$ winding) and valve side winding (ay winding), respectively.

In this paper, the mathematical model of the new converter transformer is based on voltage ratio which is equal to $1\left(\mathrm{U}_{\mathrm{AB}} / \mathrm{U}_{\mathrm{ab}}=1\right)$, so the values of $\mathrm{k}_{\mathrm{a}}$ and $\mathrm{k}_{\mathrm{x}}$ are:

$$
\begin{aligned}
& k_{a}=W_{3} / W_{1}=0.5176 \\
& k_{x}=W_{2} / W_{1}=\sqrt{3} k_{x}=0.8966
\end{aligned}
$$

\subsection{The short-circuit impedance of the new converter transformer}

For the converter transformer, the short-circuit impedance is an important parameter. Firstly, the short-circuit impedance is a unique parameter that can represent the transformer in the equivalent diagram of the power system, from which some of the operational parameters of the transformer could be calculated, such as the voltage loss, power loss, or the short-circuit current. Secondly, in the LCC DC transmission system, the short-circuit inductance of the transformer with the inductance of the power supply together is involved in the commutation process of the valves, so the value of the short-circuit inductance of the transformer is necessary to calculate the DC voltage drop and commutation angle. Finally, in the 12-pulse converter, one essential condition for successful parallel operation of the transformers is that the short-circuit impedances of two transformers must be identical to avoid unsymmetrical operation which leads to some unexpected problems such as over-voltages, over-load for one transformer. Thus, it is necessary to exactly calculate the values of these short-circuit impedances [11-15].

The new converter transformer has particular winding schemes with its filters connected to common winding of the transformer, so its short-circuit impedances are more complex than the conventional 
transformer. The first research on the short-circuit impedance of the new converter transformer was performed by $\mathrm{Mr}$. Xu [16], where the mathematical equation of the grid side short-circuit impedance for the Y/ZF-1 transformer was established as follows

$$
\begin{aligned}
& Z_{S C}=Z_{31}+k_{a} k_{x} Z_{1} \frac{Z_{f}\left(1-e^{j 120^{\circ}}\right)-k_{a} k_{x} Z_{1}}{\left(1-e^{j 120^{\circ}}\right)\left(1-e^{-j 120^{\circ}}\right) Z_{f}+Z_{21}}- \\
& \frac{Z_{21} e^{-j 120^{\circ}}}{\sqrt{3} e^{j 30^{0}}} \frac{Z_{f}\left(1-e^{j 120^{\circ}}\right)-k_{a} k_{x} Z_{1}}{\left(1-e^{j 120^{0}}\right)\left(1-e^{-j 120^{\circ}}\right) Z_{f}+Z_{21}}-\frac{k_{a} k_{x} Z_{1} e^{-j 120^{\circ}}}{\sqrt{3} e^{j 30^{0}}}
\end{aligned}
$$

The above equation shows that the short-circuit impedance depends on the equivalent impedance of the filters. This equation is a very complex mathematical relation, and it is not enough to analyze the characteristic of the short-circuit impedances of the Y/ZF-1 and Y/ZF-2 new converter transformers.

In this paper, the valve side and grid side short-circuit impedances of the Y/ZF-1 and Y/ZF-2 transformers will be established, from which we can analyze the effects of filters on the short-circuit impedances, analyze the symmetrical characteristic between the grid side short-circuit and the valve side short-circuit, and also analyze the symmetrical characteristic of the short-circuit impedances between the Y/ZF-1 and Y/ZF-2 transformers.

Finally, simulation and experiments will be performed to verify the theoretical analysis.

\section{THE SHORT-CIRCUIT IMPEDANCES OF THE NEW CONVERTER TRANSFORMER}

\subsection{The short-circuit impedances of the Y/ZF-1 transformer}

\section{a. The valve side short-circuit}

Figure 3 shows diagram of the valve side short-circuit of the Y/ZF-1 transformer, where $Z_{\mathrm{f}}$ is the equivalent impedance at the fundamental frequency of the filters.
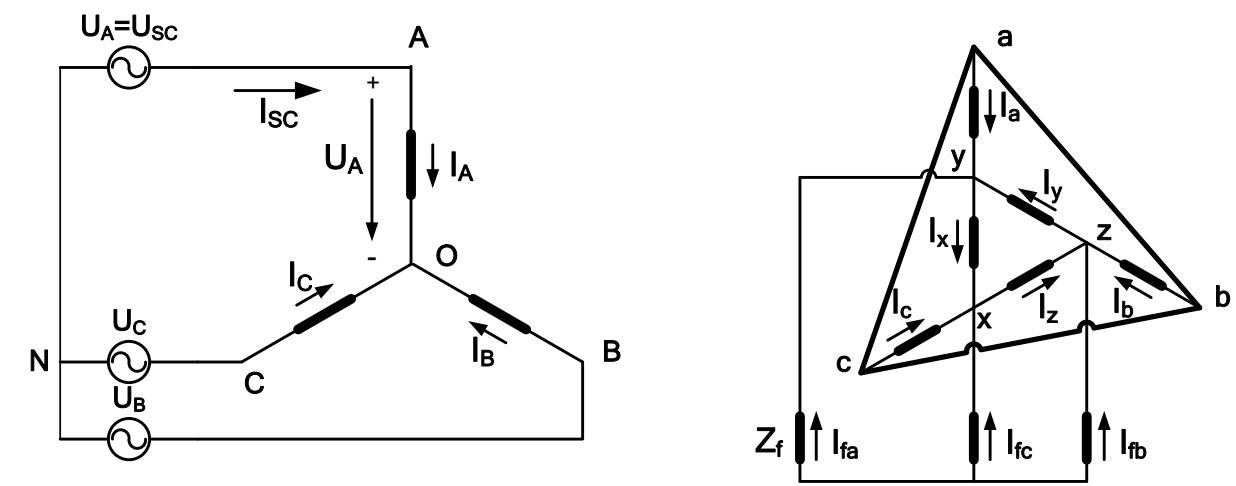

Figure 3 The principle diagram of valve side short-circuit of Y/ZF-1 transformer

Because the valve side is short-circuited, so

$$
\dot{U}_{a b}=\dot{U}_{b c}=\dot{U}_{c a}=0
$$

The filter current is obtained by Kirchhoff's Current Law:

$$
\dot{I}_{f a}=\dot{I}_{x}-\dot{I}_{y}-\dot{I}_{a}=\sqrt{3} e^{j 30^{0}} \dot{I}_{x}-\dot{I}_{a}
$$

The relationship between the voltage and the current of the filters can be expressed by the filters impedance $Z_{f}$ :

$$
\dot{U}_{y x}=Z_{f}\left(\dot{I}_{f c}-\dot{I}_{f a}\right)=\sqrt{3} e^{j 150^{\circ}} Z_{f} \dot{I}_{f a}
$$

By substituting (5) into (2):

$$
k_{x} \dot{U}_{A}+k_{x}^{2} Z_{12} \dot{I}_{x}+k_{a} k_{x} Z_{1} \dot{I}_{a}=\sqrt{3} e^{j 150^{\circ}} Z_{f} \dot{I}_{f a}
$$


By substituting (4) into (6), the relationship between the valve side current and the common side current can be obtained as

$$
\begin{aligned}
& k_{x} \dot{U}_{A}+k_{x}^{2} Z_{12} \dot{I}_{x}+k_{a} k_{x} Z_{1} \dot{I}_{a}=\sqrt{3} e^{j 150^{0}} Z_{f}\left(\sqrt{3} e^{j 30^{0}} \dot{I}_{x}-\dot{I}_{a}\right) \\
& \Rightarrow \dot{I}_{x}\left(3 Z_{f}+k_{x}^{2} Z_{12}\right)+\dot{I}_{a}\left(\sqrt{3} e^{j 150^{\circ}} Z_{f}+k_{a} k_{x} Z_{1}\right)=-k_{x} \dot{U}_{A}
\end{aligned}
$$

By combining (7) and (1):

$$
\left\{\begin{array}{l}
\dot{I}_{x}\left(3 Z_{f}+k_{x}^{2} Z_{12}\right)+\dot{I}_{a}\left(\sqrt{3} e^{j 150^{\circ}} Z_{f}+k_{a} k_{x} Z_{1}\right)=-k_{x} \dot{U}_{A} \\
k_{x} \dot{I}_{x}+k_{a} \dot{I}_{a}=-\dot{I}_{A}
\end{array}\right.
$$

By solving the equation system (8), the results are

$$
\left\{\begin{array}{l}
\dot{I}_{x}=\frac{-k_{a} k_{x} \dot{U}_{A}+\dot{I}_{A}\left(\sqrt{3} e^{j 150^{0}} Z_{f}+k_{a} k_{x} Z_{1}\right)}{3 e^{-j 15^{0}} Z_{f}+k_{a} k_{x}^{2}\left(Z_{12}-Z_{1}\right)} \\
\dot{I}_{a}=\frac{k_{x}^{2} \dot{U}_{A}-\dot{I}_{A}\left(3 Z_{f}+k_{x}^{2} Z_{12}\right)}{3 e^{-j 15^{0}} Z_{f}+k_{a} k_{x}^{2}\left(Z_{12}-Z_{1}\right)}
\end{array}\right.
$$

Also, from Figure 3 and noting that $\dot{U}_{a c}=0$ :

$$
\begin{aligned}
& \dot{U}_{a c}=\dot{U}_{a y}+\dot{U}_{y x}-\dot{U}_{c x}=0 \\
& \Rightarrow \dot{U}_{y x}=\dot{U}_{c x}-\dot{U}_{a y}=\dot{U}_{a y}\left(e^{j 120^{\circ}}-1\right)=\sqrt{3} e^{j 150^{\circ}} \dot{U}_{a y}
\end{aligned}
$$

By substituting (2) into (10):

$$
\begin{aligned}
& k_{x} \dot{U}_{A}+k_{x}^{2} Z_{12} \dot{I}_{x}+k_{a} k_{x} Z_{1} \dot{I}_{a}=\sqrt{3} e^{j 150^{\circ}}\left(k_{a} \dot{U}_{A}+k_{a}^{2} Z_{13} \dot{I}_{a}+k_{a} k_{x} Z_{1} \dot{I}_{x}\right) \\
& \Rightarrow\left(k_{x}^{2} Z_{12}-\sqrt{3} e^{j 150^{\circ}} k_{a} k_{x} Z_{1}\right) \dot{I}_{x}+\left(k_{a} k_{x} Z_{1}-\sqrt{3} e^{j 150^{\circ}} k_{a}^{2} Z_{13}\right) \dot{I}_{a} \\
& =\sqrt{3} e^{j 150^{\circ}} k_{a} \dot{U}_{A}-k_{x} \dot{U}_{A}
\end{aligned}
$$

By substituting (9) into (11):

$$
\begin{aligned}
& \left(k_{x}^{2} Z_{12}-\sqrt{3} e^{j 150^{\circ}} k_{a} k_{x} Z_{1}\right) \frac{-k_{a} k_{x} \dot{U}_{A}+\dot{I}_{A}\left(\sqrt{3} e^{j 150^{\circ}} Z_{f}+k_{a} k_{x} Z_{1}\right)}{3 e^{-j 15^{0}} Z_{f}+k_{a} k_{x}^{2}\left(Z_{12}-Z_{1}\right)} \\
& +\left(k_{a} k_{x} Z_{1}-\sqrt{3} e^{j 150^{0}} k_{a}^{2} Z_{13}\right) \frac{k_{x}^{2} \dot{U}_{A}-\dot{I}_{A}\left(3 Z_{f}+k_{x}^{2} Z_{12}\right)}{3 e^{-j 15^{0}} Z_{f}+k_{a} k_{x}^{2}\left(Z_{12}-Z_{1}\right)}=\sqrt{3} e^{j 150^{0}} k_{a} \dot{U}_{A}-k_{x} \dot{U}_{A}
\end{aligned}
$$

The equation (12) can be written as

$$
A \dot{U}_{A}=\left(B_{1}+B_{2}\right) \dot{I}_{A}
$$

where $A$ is a voltage factor, $B_{1}$ is a current factor with $Z_{f}, B_{2}$ is a current factor without including $Z_{f}$ :

$$
\left\{\begin{array}{l}
A=\sqrt{3} e^{-j 30^{0}}\left[3 Z_{f}+k_{a}^{2} k_{x}^{2}\left(Z_{12}+Z_{13}-2 Z_{1}\right)\right] \\
B_{1}=\sqrt{3} e^{-j 30^{0}}\left[3 Z_{f} Z_{k}\right] \\
B_{2}=\sqrt{3} e^{-j 30^{0}} k_{a}^{2} k_{x}^{2}\left[Z_{12} Z_{13}-Z_{1}^{2}\right]
\end{array}\right.
$$

In equations (14), $Z_{\mathrm{k}}$ is obtained as:

$$
Z_{k}=k_{a}^{2}\left(Z_{12}+Z_{13}+\sqrt{3} Z_{1}\right)
$$

From (13) and (14), the valve side short-circuit impedance can be obtained by 


$$
\begin{aligned}
& Z_{S C}=\frac{\dot{U}_{S C}}{\dot{I}_{S C}}=\frac{\dot{U}_{A}}{\dot{I}_{A}}=\frac{B_{1}+B_{2}}{A} \\
& =\frac{3 Z_{f} Z_{k}+k_{a}^{2} k_{x}^{2}\left[Z_{12} Z_{13}-Z_{1}^{2}\right]}{3 Z_{f}+k_{a}^{2} k_{x}^{2}\left(Z_{12}+Z_{13}-2 Z_{1}\right)}
\end{aligned}
$$

\section{b. The grid side short-circuit}

The principle diagram of the grid side short-circuit of the Y/ZF-1 transformer is shown in Figure 4
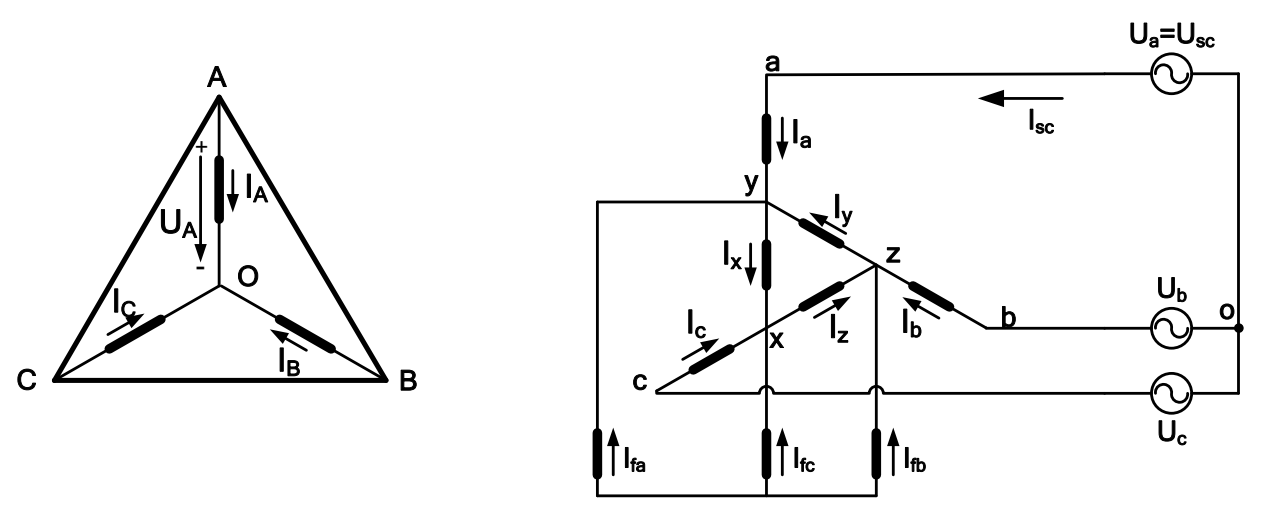

Figure 4 The principle diagram of grid side short-circuit of Y/ZF-1 transformer

From Figure 4, because the grid side is short-circuited, so

$$
\begin{aligned}
& \dot{U}_{A B}=\dot{U}_{B C}=\dot{U}_{C A}=0 \\
& \Rightarrow \dot{U}_{A}=\dot{U}_{B}=\dot{U}_{C}=0
\end{aligned}
$$

By substituting (17) into (2):

$$
\dot{U}_{y x}=k_{x}^{2} Z_{12} \dot{I}_{x}+k_{a} k_{x} Z_{1} \dot{I}_{a}
$$

The relationship between the voltage and current of the filters can be expressed by the filter impedance:

$$
\dot{U}_{y x}=Z_{f}\left(\dot{I}_{f c}-\dot{I}_{f a}\right)=\sqrt{3} e^{j 150^{\circ}} Z_{f} \dot{I}_{f a}
$$

By combining (18) and (19):

$$
\sqrt{3} e^{j 150^{\circ}} Z_{f} \dot{I}_{f a}=k_{x}^{2} Z_{12} \dot{I}_{x}+k_{a} k_{x} Z_{1} \dot{I}_{a}
$$

The filter current is obtained by Kirchhoff's Current Law:

$$
\dot{I}_{f a}=\dot{I}_{x}-\dot{I}_{y}-\dot{I}_{a}=\sqrt{3} e^{j 30^{0}} \dot{I}_{x}-\dot{I}_{a}
$$

By substituting (21) into (20), the relationship of the currents between the valve side and the common side can be obtained as

$$
\begin{aligned}
& \sqrt{3} e^{j 150^{\circ}} Z_{f}\left(\sqrt{3} e^{j 30^{0}} \dot{I}_{x}-\dot{I}_{a}\right)=k_{x}^{2} Z_{12} \dot{I}_{x}+k_{a} k_{x} Z_{1} \dot{I}_{a} \\
& \Rightarrow \dot{I}_{x}=-\frac{\sqrt{3} e^{j 150^{\circ}} Z_{f}+k_{a} k_{x} Z_{1}}{3 Z_{f}+k_{x}^{2} Z_{12}} \dot{I}_{a}
\end{aligned}
$$

Also, from Figure 4:

$$
\dot{U}_{a b}=\dot{U}_{a y}-\dot{U}_{b z}-\dot{U}_{z y}=\dot{U}_{a y}\left(1-e^{-j 120^{\circ}}\right)-\dot{U}_{y x} e^{-j 120^{\circ}}=\sqrt{3} e^{j 30^{0}}\left(\dot{U}_{a y}-\frac{\dot{U}_{y x}}{\sqrt{3}} e^{-j 150^{\circ}}\right)
$$

By using the phase voltage quantity, (23) can be written as 


$$
\dot{U}_{a o}=\left(\dot{U}_{a y}-\frac{\dot{U}_{y x}}{\sqrt{3}} e^{-j 150^{\circ}}\right)
$$

By substituting (2) into (24):

$$
\begin{aligned}
& \dot{U}_{a o}=\left(k_{a}^{2} Z_{13} \dot{I}_{a}+k_{a} k_{x} Z_{1} \dot{I}_{x}\right)-\frac{e^{-j 150^{\circ}}}{\sqrt{3}}\left(k_{x}^{2} Z_{12} \dot{I}_{x}+k_{a} k_{x} Z_{1} \dot{I}_{a}\right) \\
& \Rightarrow \dot{U}_{a o}=\dot{I}_{a}\left(k_{a}^{2} Z_{13}-\frac{e^{-j 150^{\circ}}}{\sqrt{3}} k_{a} k_{x} Z_{1}\right)+\dot{I}_{x}\left(k_{a} k_{x} Z_{1}-\frac{e^{-j 150^{\circ}}}{\sqrt{3}} k_{x}^{2} Z_{12}\right)
\end{aligned}
$$

By substituting (22) into (25), the phase voltage of the valve side can be deduced by

$$
\begin{aligned}
& \dot{U}_{a o}=\dot{I}_{a}\left(k_{a}^{2} Z_{13}-\frac{e^{-j 150^{\circ}}}{\sqrt{3}} k_{a} k_{x} Z_{1}\right)-\dot{I}_{a} \frac{\sqrt{3} e^{j 150^{\circ}} Z_{f}+k_{a} k_{x} Z_{1}}{3 Z_{f}+k_{x}^{2} Z_{12}}\left(k_{a} k_{x} Z_{1}-\frac{e^{-j 150^{\circ}}}{\sqrt{3}} k_{x}^{2} Z_{12}\right) \\
& \Rightarrow \dot{U}_{a o}=\frac{3 Z_{f} Z_{k}+k_{a}^{2} k_{x}^{2}\left(Z_{12} Z_{13}-Z_{1}^{2}\right)}{3 Z_{f}+k_{x}^{2} Z_{12}} \dot{I}_{a}
\end{aligned}
$$

where $Z_{\mathrm{k}}$ is the same as in equation (15).

The grid side short-circuit impedance of the Y/ZF-1 transformer can be obtained by:

$$
Z_{s c}=\frac{\dot{U}_{s c}}{\dot{I}_{s c}}=\frac{\dot{U}_{a o}}{\dot{I}_{a}}=\frac{3 Z_{f} Z_{k}+k_{a}^{2} k_{x}^{2}\left(Z_{12} Z_{13}-Z_{1}^{2}\right)}{3 Z_{f}+k_{x}^{2} Z_{12}}
$$

\subsection{The short-circuit impedances of the Y/ZF-2 transformer}

\section{a. The valve side short-circuit}

The principle diagram of the valve side short-circuit of the Y/ZF-2 transformer is shown in Figure 5, where $\mathrm{Z}_{\mathrm{f}}$ is the equivalent impedance at the fundamental frequency of the filters
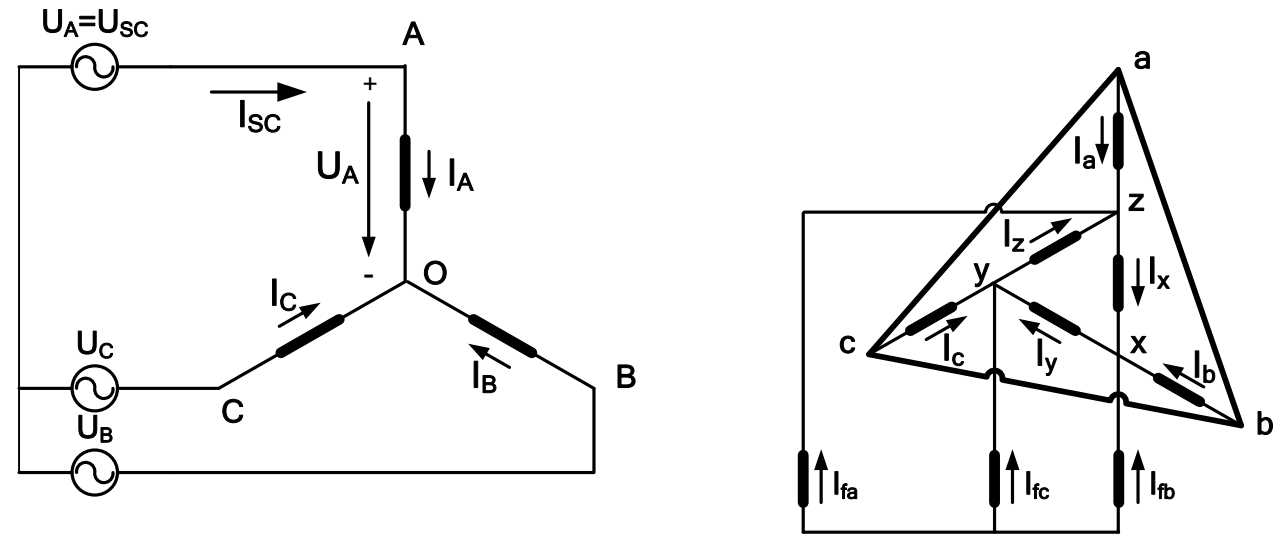

Figure 5 The principle diagram of valve side short-circuit of Y/ZF-2 transformer

As the same manner with the Y/ZF-2 transformer, the valve side short-circuit impedance of Y/ZF-2 can be obtained by

$$
Z_{S C}=\frac{\dot{U}_{S C}}{\dot{I}_{S C}}=\frac{\dot{U}_{A}}{\dot{I}_{A}}=\frac{3 Z_{f} Z_{k}+k_{a}^{2} k_{x}^{2}\left[Z_{12} Z_{13}-Z_{1}^{2}\right]}{3 Z_{f}+k_{a}^{2} k_{x}^{2}\left(Z_{12}+Z_{13}-2 Z_{1}\right)}
$$

\section{b. The grid side short-circuit}

The principle diagram of the grid side short-circuit of the Y/ZF-2 transformer is shown in Figure 6. 

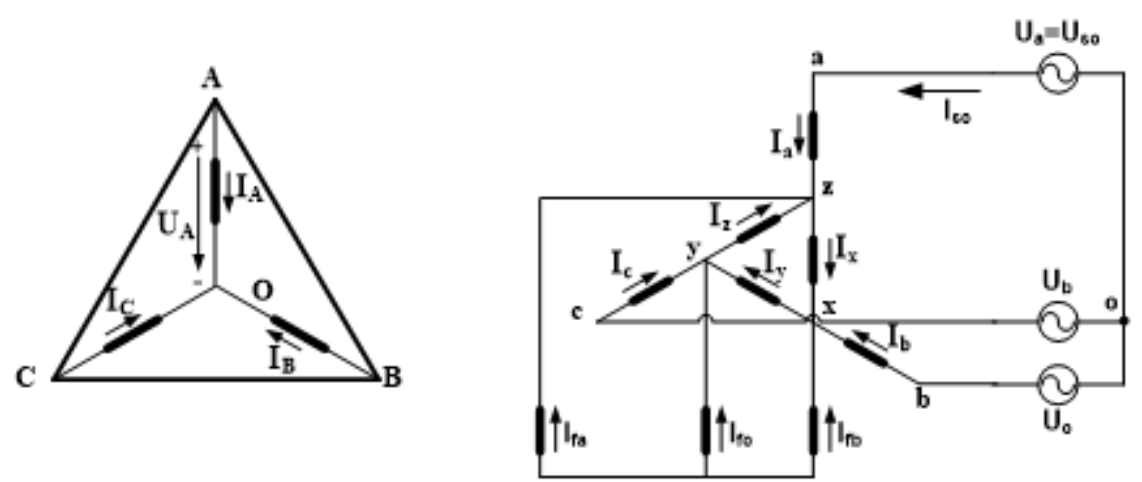

Figure 6 The principle diagram of grid side short-circuit of Y/ZF-2 transformer

As the same manner with the Y/ZF-2 transformer, the grid side short-circuit impedance of Y/ZF-2 can be obtained by

$$
Z_{s c}=\frac{\dot{U}_{s c}}{\dot{I}_{s c}}=\frac{\dot{U}_{a o}}{\dot{I}_{a}}=\frac{3 Z_{f} Z_{k}+k_{a}^{2} k_{x}^{2}\left(Z_{12} Z_{13}-Z_{1}^{2}\right)}{3 Z_{f}+k_{x}^{2} Z_{12}} \dot{I}_{a}
$$

\section{THE CHARACTERISTIC OF THE SHORT-CIRCUIT IMPEDANCES OF THE NEW CONVERTER TRANSFORMER}

From (16), (27), (28) and (29), the short-circuit impedances of the grid side and valve side of the Y/ZF-1 and Y/ZF-2 transformers are rewritten in Table 1

Table 1 The short-circuit impedances of Y/ZF-1 and Y/ZF-2 transformers

\begin{tabular}{|c|c|c|}
\hline Transformer & $\begin{array}{c}\text { The valve side short-circuit } \\
Z_{\mathrm{SC}}\end{array}$ & $\begin{array}{c}\text { The grid side short-circuit } \\
Z_{\mathrm{sc}}\end{array}$ \\
\hline Y/ZF-1 & $\frac{3 Z_{f} Z_{k}+k_{a}^{2} k_{x}^{2}\left[Z_{12} Z_{13}-Z_{1}^{2}\right]}{3 Z_{f}+k_{a}^{2} k_{x}^{2}\left(Z_{12}+Z_{13}-2 Z_{1}\right)}$ & $\frac{3 Z_{f} Z_{k}+k_{a}^{2} k_{x}^{2}\left(Z_{12} Z_{13}-Z_{1}^{2}\right)}{3 Z_{f}+k_{x}^{2} Z_{12}}$ \\
\hline Y/ZF-2 & $\frac{3 Z_{f} Z_{k}+k_{a}^{2} k_{x}^{2}\left[Z_{12} Z_{13}-Z_{1}^{2}\right]}{3 Z_{f}+k_{a}^{2} k_{x}^{2}\left(Z_{12}+Z_{13}-2 Z_{1}\right)}$ & $\frac{3 Z_{f} Z_{k}+k_{a}^{2} k_{x}^{2}\left(Z_{12} Z_{13}-Z_{1}^{2}\right)}{3 Z_{f}+k_{x}^{2} Z_{12}}$ \\
\hline
\end{tabular}

The short-circuit impedances of the Y/ZF-1 and Y/ZF-2 transformers in Table 1 depend on the filters impedance $Z_{\mathrm{f}}$ which depends on the filters reactive power.

Without filters, $Z_{f}=\infty$, the short-circuit impedances of the Y/ZF-1 and Y/ZF-2 transformers in Table 1 can be expressed as shown in Table 2

Table 2 The short-circuit impedances without filters

\begin{tabular}{|c|c|c|}
\hline \multirow{2}{*}{ Transformers } & $\begin{array}{c}\text { The valve side short-circuit } \\
Z_{\mathrm{SC}}\end{array}$ & $\begin{array}{c}\text { The grid side short-circuit } \\
\mathrm{Z}_{\mathrm{sc}}\end{array}$ \\
\hline Y/ZF-1 & $Z_{k}$ & $Z_{k}$ \\
\hline Y/ZF-2 & $Z_{k}$ & $Z_{k}$ \\
\hline
\end{tabular}

With filter $\left(Z_{f} \neq \infty\right)$, the relationships of the filters impedance and the transformer impedances are can be obtained by: 


$$
\left\{\begin{array}{l}
\left|3 Z_{f}\right|>>k_{a}^{2} k_{x}^{2}\left|\left(Z_{12}+Z_{13}-2 Z_{1}\right)\right| \\
\left|3 Z_{f} Z_{k}\right|>>k_{a}^{2} k_{x}^{2}\left|Z_{12} Z_{13}-Z_{1}^{2}\right|
\end{array}\right.
$$

By substituting (30) into Table 1, the approximate short-circuit impedances of the Y/ZF-1 and Y/ZF2 transformers are deduced in Table 3

Table 3 The approximate short-circuit impedances with filters

\begin{tabular}{|c|c|c|}
\hline \multirow{2}{*}{ Transformers } & $\begin{array}{c}\text { The valve side short-circuit } \\
\mathrm{Z}_{\mathrm{SC}}\end{array}$ & $\begin{array}{c}\text { The grid side short-circuit } \\
\mathrm{Z}_{\mathrm{sc}}\end{array}$ \\
\hline Y/ZF-1 & $Z_{k}$ & $Z_{k}$ \\
\hline Y/ZF-2 & $Z_{k}$ & $Z_{k}$ \\
\hline
\end{tabular}

Note that the $\mathrm{Z}_{\mathrm{k}}$ is obtained by (15) as:

$$
Z_{k}=k_{a}^{2}\left(Z_{12}+Z_{13}+\sqrt{3} Z_{1}\right)
$$

Table 2 and Table 3 are obviously identical. By analysis of these tables, the results show that:

- The short-circuit impedances of the Y/ZF-1 and Y/ZF-2 transformers are identical, so it obviously demonstrates that the Y/ZF-1 and Y/ZF-2 transformers can operate in the 12-pulse converter system.

- The grid side and valve side short-circuit impedances are almost the same and approximately equal to the Zk for both Y/ZF-1 and Y/ZF-2 transformers, so the short-circuit impedances of the grid side and valve side are almost symmetrical.

\section{THE SIMULATION AND EXPERIMENT}

\section{a. The simulation and experimental models}

The new converter transformer consists of three single-phase three-winding transformers. The main technical parameters of a single transformer are as follows: $S=17.9 \mathrm{kVA}$, rated voltages are $196.7 / 220 / 116 \mathrm{~V}$, the short-circuit impedances are $Z_{12}=0.4549 \angle 78.0^{\circ}(\Omega), Z_{13}=0.6576 \angle 79.5^{\circ}(\Omega)$ and $Z_{23}=0.2464 \angle 66.4^{0}(\Omega)$.

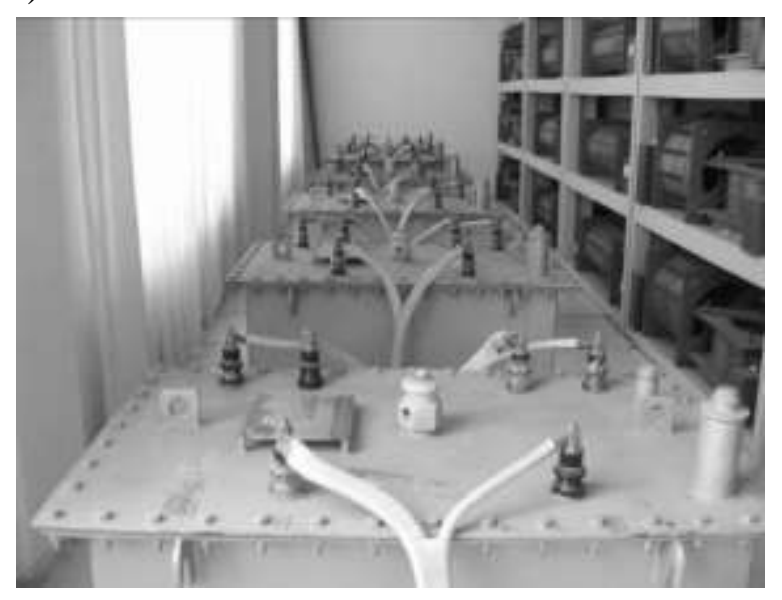

Figure 7 The single-phase three-winding transformers

The AC filters for the Y/ZF-1 and Y/ZF-2 transformers are single-tuned $5^{\text {th }}, 7^{\text {th }}, 11^{\text {th }}$, and $13^{\text {th }}$ order filters, with the total reactive power and impedance at the fundamental frequency being $\mathrm{Q}_{\mathrm{f}}=10.4 \mathrm{kVAR}$ and $Z_{f}=3.72 \angle-90^{\circ}(\Omega)$, respectively.

The experiment uses the 3196 Hioki quality power analyzer to record and analyze the experimental datas. 
The simulation uses the Matlab/simulink software with parameters of the transformer and the filters being the same with the experimental platform. Figure 8 shows the simulation diagram of the short-circuit test for Y/ZF-1 transformer.

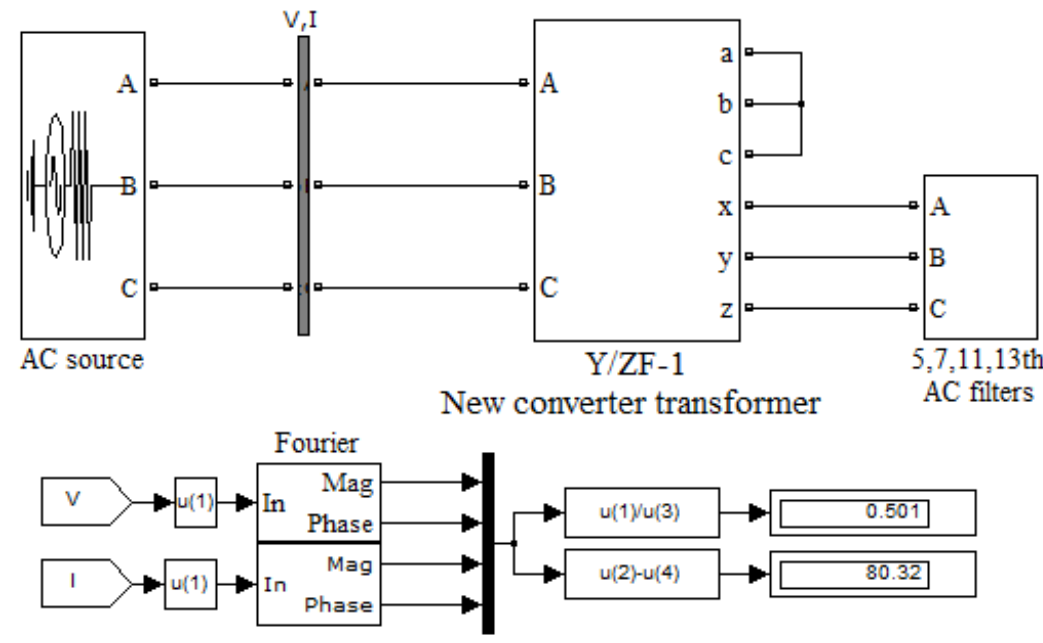

Figure 8 The simulation diagram of the short-circuit test

\section{b. The simulation and experimental results}

Figure 9 shows the vector diagram of experimental voltages and currents of the Y/ZF-1 transformer with and without filters under valve side short-circuit condition. And Figure 10 shows the same results under the grid side short-circuit condition.

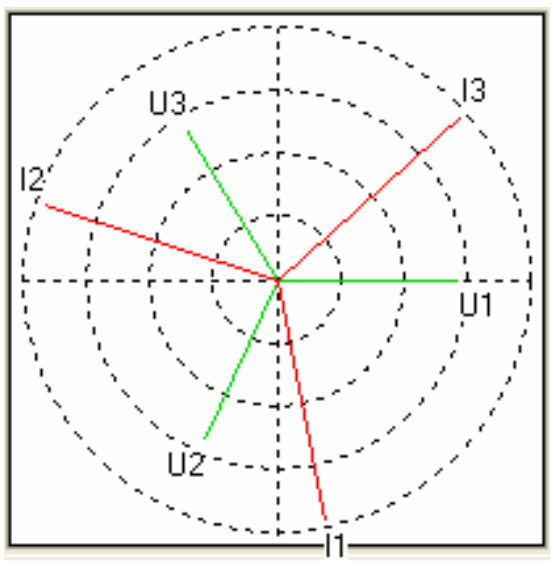

(a) without filters

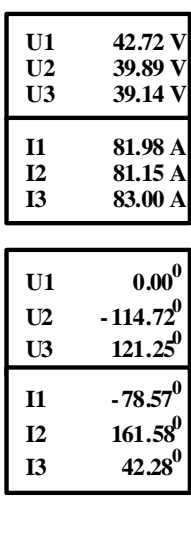

$61.58^{0}$
$42.28^{0}$

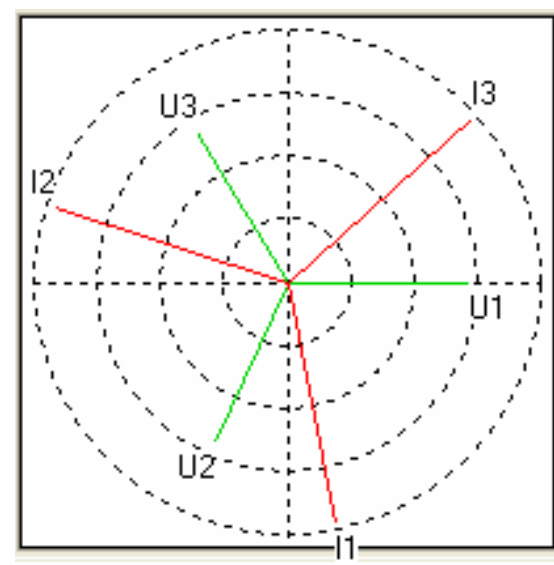

(b) with filters,

\begin{tabular}{|c|c|}
\hline $\begin{array}{l}\text { U1 } \\
\text { U2 } \\
\text { U3 }\end{array}$ & $\begin{array}{l}41.93 \mathrm{~V} \\
39.22 \mathrm{~V} \\
38.64 \mathrm{~V}\end{array}$ \\
\hline $\begin{array}{l}\text { I1 } \\
\text { I2 } \\
\text { I3 }\end{array}$ & $\begin{array}{l}80.58 \mathrm{~A} \\
79.72 \mathrm{~A} \\
81.76 \mathrm{~A}\end{array}$ \\
\hline $\begin{array}{l}\text { U1 } \\
\text { U2 } \\
\text { U3 }\end{array}$ & $\begin{array}{r}0.00^{0} \\
-114.81^{0} \\
121.01^{0}\end{array}$ \\
\hline $\begin{array}{l}\text { I1 } \\
\text { I2 } \\
\text { I3 }\end{array}$ & $\begin{array}{r}-78.56^{0} \\
161.61^{0} \\
42.00^{0}\end{array}$ \\
\hline
\end{tabular}

Figure 9 The experimental results of valve side short-circuit of Y/ZF-1 transformer 


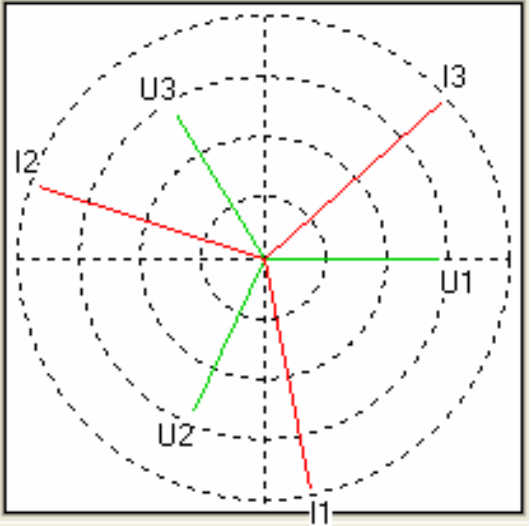

(a) without filters

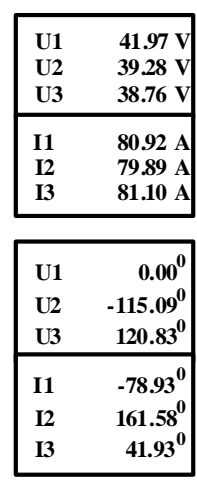

Table 4: The short-circuit impedances.

\begin{tabular}{|c|c|c|c|c|c|}
\hline \multirow{2}{*}{ Trans } & \multirow{2}{*}{$\mathrm{Z}_{\mathrm{f}}(\Omega)$} & \multicolumn{2}{|c|}{$\begin{array}{c}\text { The valve side short-circuit } \\
\text { impedances }(\Omega)\end{array}$} & \multicolumn{2}{|c|}{$\begin{array}{c}\text { The grid side short-circuit impedances } \\
(\Omega)\end{array}$} \\
\cline { 3 - 6 } & & $\begin{array}{c}\text { Experimental } \\
\text { results }\end{array}$ & $\begin{array}{c}\text { Simulation } \\
\text { results }\end{array}$ & $\begin{array}{c}\text { Experimental } \\
\text { results }\end{array}$ & $\begin{array}{c}\text { Simulation } \\
\text { results }\end{array}$ \\
\hline \multirow{2}{*}{$\begin{array}{c}\mathbf{Y} / \mathbf{Z F}- \\
\mathbf{1}\end{array}$} & $\infty$ & $0.495 \angle 80.4^{0}$ & $0.501 \angle 80.3^{0}$ & $0.496 \angle 80.4^{0}$ & $0.497 \angle 80.3^{0}$ \\
\cline { 2 - 6 } & $3.72 \angle 90^{0}$ & $0.495 \angle 80.4^{0}$ & $0.501 \angle 80.3^{0}$ & $0.509 \angle 80.3^{0}$ & $0.511 \angle 80.0^{0}$ \\
\hline \multirow{2}{*}{$\mathbf{Y} / \mathbf{Z F}-$} & $\infty$ & $0.495 \angle 80.4^{0}$ & $0.501 \angle 80.3^{0}$ & $0.495 \angle 80.5^{0}$ & $0.497 \angle 80.3^{0}$ \\
\cline { 2 - 6 } $\mathbf{2}$ & $3.72 \angle 90^{0}$ & $0.495 \angle 80.4^{0}$ & $0.501 \angle 80.3^{0}$ & $0.507 \angle 80.4^{0}$ & $0.511 \angle 80.0^{0}$ \\
\hline
\end{tabular}

Based on the analysis of Table 4, the results show that (use the experimental results to illustrate):

- The symmetrical characteristic of the Y/ZF-1 and Y/ZF-2: the valve side short-circuit impedances of the Y/ZF-1 and Y/ZF-2 transformer are identical and equal to $0.495 \Omega$; while that of grid side shortcircuit are almost the same. For example, the grid side short-circuit impedance of Y/ZF-1 without filters is $0.496 \Omega$, and that of $Y / Z F-2$ is $0.495 \Omega$. So the short-circuit impedances of the Y/ZF-1 and Y/ZF-2 transformers are almost identical.

- The symmetrical characteristic of valve side and grid side short-circuit: The valve side and grid side short-circuit impedances of the Y/ZF-1 and Y/ZF-2 transformers are slightly different. For example, the valve side short-circuit impedance of the $\mathrm{Y} / \mathrm{ZF}-1$ without filters is $0.495 \Omega$ and that of grid side shortcircuit is $0.496 \Omega$. So the grid side and valve side short-circuit impedances of the $\mathrm{Y} / \mathrm{ZF}-1$ and $\mathrm{Y} / \mathrm{ZF}-2$ transformers are almost symmetrical.

\section{CONCLUSIONS}

Based on the winding connection diagram of the Y/ZF-1 and Y/ZF-2 new converter transformers, the mathematical relationship between the valve side short-circuit impedance $Z_{\mathrm{SC}}$, the grid side short-circuits 
impedance $Z_{s c}$ and the filter impedance $Z_{f}$ have been established, respectively. According to the comparison between the short-circuit impedances of the Y/ZF-1 and Y/ZF-2 transformers, it shows that the short-circuit impedance of both transformers are almost identical. Moreover, based on comparing the valve side short-circuit impedance $Z_{\mathrm{SC}}$ and the grid side short-circuit impedance $Z_{\mathrm{sc}}$, the results show that both short-circuit impedances are almost the same, so that the short-circuit impedances of the Y/ZF-1 and Y/ZF-2 new converter transformers are symmetrical.

Finally, the simulation and experimental results verified the correctness of the theoretical analysis.

\section{APPENDIX}

\section{REFERENCES}

[1] B. Wu, High-Power Converters and AC Drives. Wiley-IEEE Press, 2017.

[2] Mircea Eremia, Chen-Ching Liu, Advanced Solutions in Power Systems: HVDC, FACTS, and Artificial Intelligence. IEEE Press, 2016.

[3] Dragan Jovcic, Khaled Ahmed, High Voltage Direct Current Transmission: Converters, Systems and DC Grids, John Wiley \& Sons, 2015.

[4] M. P. Bahrman and B. K. Johnson, The ABCs of HVDC transmission technologies, IEEE Power Energy Mag, vol. 5, pp. 32-44, Mar.-Apr 2007.

[5] L. F. Luo, Y. Li, J. Z. Xu, J. Li, B. Hu, and F. S. Liu, A new converter transformer and a corresponding inductive filtering method for HVDC transmission system, IEEE Trans. Power Del., vol. 23, no. 3, pp. 14261431, Jul. 2008.

[6] Y. Li, L. F. Luo, C. Rehtanz, K. Nakamura, J. Z. Xu, and F. S. Liu, Study on characteristic parameters of a new converter transformer for HVDC systems, IEEE Trans. Power Del., vol. 24, no. 4, pp. 2125- 2131, Oct. 2009.

[7] L. Luo, Y. Li, K. Nakamura, G. Krost, J. Li, J. Xu and F. Liu, Harmonic characteristics of new HVDC transmission system based on new converter transformer, in 3rd International Conference on Deregulation and Restructuring and Power Technologies, DRPT 2008, 2008, pp. 1868-1872.

[8] Y. Li, L. Luo, C. Rehtanz, D. Yang, S. Rüberg, F. Liu, "Harmonic transfer characteristics of a new HVDC system based on an inductive filtering method", IEEE Trans. Power Electron., vol. 27, no. 5, pp. 2273-2283, May 2012.

[9] T. N. Tran et al., "Analysis of the characteristics of the new converter transformer based on the matrix model", IEEE Trans. Power Del., vol. 27, no. 2, pp. 821-830, Apr. 2012.

[10] Shayma'a M. Kamal ; Mostafa S. Hamad ; Ragi A. R. Hamdy ; Amr ElZawawi, Influence of a proposed converter transformer on harmonic suppression for HVDC systems, Nineteenth International Middle East Power Systems Conference (MEPCON), Dec. 2017.

[11]Feng Wang ; Chunning Wang, Parameters' calculation for converter transformer in HVDC system, 2014 China International Conference on Electricity Distribution (CICED), December 2014

[12] Shoaib Khan, Industrial Power Systems. CRC Press, 2007.

[13] J. Schlabbach, Short-circuit Currents, London: Institution of Electrical Engineers, 2005.

[14] T. Subbarao and J. Reeve, Harmonics Caused by Imbalanced Transformer Impedances and Imperfect 12-pulse Operation, IEEE Transactions on Power Apparatus and Systems, 1976, 95(5): 1732-1737.

[15]Chan-Ki Kim, Vijay K. Sood, Gil-Soo Jang, Seong-Joo Lim, and Seok-Jin Lee, HVDC Transmission: Power Conversion Applications in Power Systems. Wiley-IEEE Press, 2009. 
[16] Xu Jiazhu, Luo Longfu, Li Ji, et al, Analysis and calculation of commutated reactance of novel converter transformer and its filter system. Transactions of China Electrotechnical Society, 2007, 22(10): 49-54 (in Chinese).

\section{NGHIÊN CỬU TRỞ KHÁNG NGẮN MẠCH CỦA MÁY BIẾN ÁP BIẾN ĐỔI KIỂU MỚI}

Tóm tắt. Trở kháng ngắn mạch của máy biến áp là một trong các thông số kỹ thuật quan trọng trong hệ thống HVDC. So với các máy biến áp biến đổi truyền thống, máy biến áp biến đổi kiểu mới có sơ đồ nối dây đặc biệt. Dựa trên cấu trúc cấu trúc của máy biến áp biến đổi kiểu mới, bài viết này đề xuất một phương pháp mới để thiết lập mối quan hệ toán học của trở kháng ngắn mạch và trở kháng của bộ lọc trong trường hợp ngắn mạch ở phía van và phía lưới. Phân tích về trở kháng ngắn mạch ở phía van và phía lưới cho thấy cả hai giá trị trở kháng ngắn mạch gần như giống nhau, do đó trở kháng của biến áp biến đổi kiểu mới là đối xứng. Cuối cùng, các kết quả mô phỏng và thực nghiệm được thực hiện đã chứng minh sự chính xác của các phân tích lý thuyết.

Từ khóa. HVDC, Máy biến áp biến đổi kiểu mới, trở kháng ngắn mạch, bộ lọc.

Ngày nhận bài:11/05/2019

Ngày chấp nhận đăng:06/06/2019 